\title{
The Relationship of Power of Statistical Tests to Range of Talent: A Correction and Amplification
}

\author{
Lloyd G. Humphreys \\ University of Illinois
}

The section on related issues in Humphreys and Drasgow (1989) contains the following statement, for which I was largely responsible: "Given identical independent variables and identical measures of the dependent variable, it is not possible to hold effect size constant from one range of talent to another" (p. 424). This statement is inaccurate, and its direct opposite is also inaccurate. A qualification is therefore required concerning the difference in effect on power of restriction of range between treatments under experimental control and categories formed from examinee (individual differences) variables.

When treatments are under experimental control and there is no interaction between the independent variables and individual differences on the dependent measure, power will increase as restriction increases, as Zimmerman and Williams (1986) concluded. Interactions can be spurious when units of measurement are not equal, and they can also be real on well-behaved scales of measurement. Both types of interactions occur with substantial frequency; therefore, obtaining an increase in power by selecting a sample with a narrow range of talent is problematic.

In contrast, when the "levels of treatment" are categories such as race and gender, there is an expected loss of power as restriction on the combined distribution of the dependent measure increases. The basis for this conclusion is identical to that for the effect of restriction on correlations between two continuous distributions after one has been dichotomized, either for convenience or by necessity. For example, selection on a predictor decreases correlations with a pass-fail criterion. [See Humphreys and Swets (1991) for a series of examples in which successive truncations are made on the same distribution.] When the "criterion"' is a category, the expectation for a loss in power is realized if the distributions within categories are approximately symmetrical and equally variable.

\section{References}

Humphreys, L. G., \& Drasgow, F. (1989). Some comments on the relation between reliability and statistical power. Applied Psychological Measurement, 13, 419-425.

Humphreys, L. G., \& Swets, J. A. (1991). Comparison of predictive validities measured with biserial correlations and ROCs of signal detection theory. Journal of Applied Psychology, 76, 316-321.

Zimmerman, D. W., \& Williams, R. H. (1986). Note on the reliability of experimental measures and the power of statistical tests. Psychological Bulletin, 100, 123-124.

\section{Author's Address}

Send requests for reprints or further information to Lloyd G. Humphreys, Department of Psychology, 603 East Daniel Street, Champaign IL 61820, U.S.A.

APPLIED PSYCHOLOGICAL MEASUREMENT

Vol. 15, No. 3, September 1991, pp. 267

(C) Copyright 1991 Applied Psychological Measurement Inc. 0146-6216/91/030267-01\$1.30 